\title{
Comparative Particle Recoveries by the Retracting Rotorod, Rotoslide and Burkard Spore Trap Sampling in a Compact Array
}

\author{
by
}

\author{
W. R. Solomon*, H. A. Burge, J. R. Boise and M. Becker
}

\begin{abstract}
An array comprising 4 intermittent (retracting) rotorods, 3 ("swingshield") rotoslides and one Burkard (Hirst) automatic volumetric spore trap was operated on an urban rooftop during 70 periods of 9,15 or 24 hours in late summer. Standard sampling procedures were utilized and recoveries of pollens as well as spores of Alternaria, Epicoccum, Pithomyces and Ganoderma species compared. Differences between paired counts from each sampler type showed variances increasing with levels of particle prevalence (and deposition). In addition, minimal, non-random, side-to-side and intersampler differences were noted for both impactor types. Exclusion of particles between operating intervals by rotoslides and rotorods was virtually complete. Spore trap recoveries for all particle categories, per $\mathrm{m}^{3}$, exceeded those by both impactors. The greatest (7-fold) difference was noted for the smallest type examined (Ganoderma). For ragweed pollen, an overall spore trap/impactor ratio approached 1.5. Rain effects were difficult to discern but seemed to influence rotoslides least. Overall differences between impactors were quite small but generally favored the rotoslide in this comparison. Our data confirm the relative advantages of suction traps for small particles. Both impactors and spore traps are suited to pollen and large spore collection, and, with some qualification, data from both may be compared.
\end{abstract}

\section{INTRODUCTION}

Microscopically identifiable, airborne biological particles have received increasing attention, recently, as plant pathogens and allergens (Gregory, 1973), as well as markers of atmospheric diffusion (Dingle, 1957; Raynor, Hayes and Ogden, 1970). Relevant studies have been encouraged and facilitated by the development of volumetric collection devices which provide recoveries from calculable volumes of air. Two major groups of samplers, with this capacity, have become commercially available: rotating arm impactors and spore traps (Solomon and Mathews, 1978).

Impactors utilize narrow, adhesive-coated surfaces which are whirled rapidly through the air. Particles in the volume swept out by the sampler may be impacted, and the efficiency of this process rises with particle size and increasing "stickiness" of the surface coating. The intermittent rotoslide and rotorod samplers exemplify this type of collector, which is little affected by variations in wind direction.

* Section of Allergy, Dept. of Internal Medicine, (Medical School) and Dept. of Epidemiology (School of Public Health), University of Michigan, Ann Arbor, Mich. 48109, USA.

Received 2 September 1979. 
108

Spore traps employ narrow orifices to accelerate measured volumes of particlebearing air. The resulting jets pass through bends in the flow channel, and those particles unable to turn fully strike the walls where collection surfaces are deployed. Volumetric recoveries-especially of larger particles-require precise wind orientation of the trap and are affected by continuously changing differences between air speed at the intake and in the free (ambient) stream (Watson, 1954). The Burkard-built (Hirst) spore trap is the most widely used sampler of this type, at present.

Given acknowledged sources of error which render both sampler types less than $100 \%$ efficient, the comparative performance of major samplers remains unclear, especially for particles above $10 \mu \mathrm{m}$. This uncertainty has hampered interregional comparisons of aeroallergen prevalence, since British and European workers, in general, use spore traps, while impactors of various types have been favored in North America. The recent commercial introduction of an intermittent operating, rotorod sampler has further increased a general need to obtain and weigh comparative, volumetric performance data.

\section{MATERIALS AND METHODS}

All studies have utilized a rooftop $17 \mathrm{~m}$ above grade in Ann Arbor. The rooftop is unobstructed for circa $300^{\circ}$ centered about the wind ward direction, although an elevator housing is present downwind. Surrounding areas are generously planted, but clearly urban, with major vehicular traffic as well as the University's heating plant upwind of the site.

A side-by-side comparison of particle recoveries by three intermittent rotoslide (Raynor and Ogden, 1970) samplers (kindly lent by Gilbert S. Raynor, Brookhaven National Laboratories, Upton, N.Y.), four intermittent retracting rotorod samplers (courtesy of the manufacturer, Ted Brown Associates, Los Altos Hills, Calif.) and a single Burkard (Hirst) spore trap (Burkard Mfg. Co., Ltd., Harpenden, Herts, England)

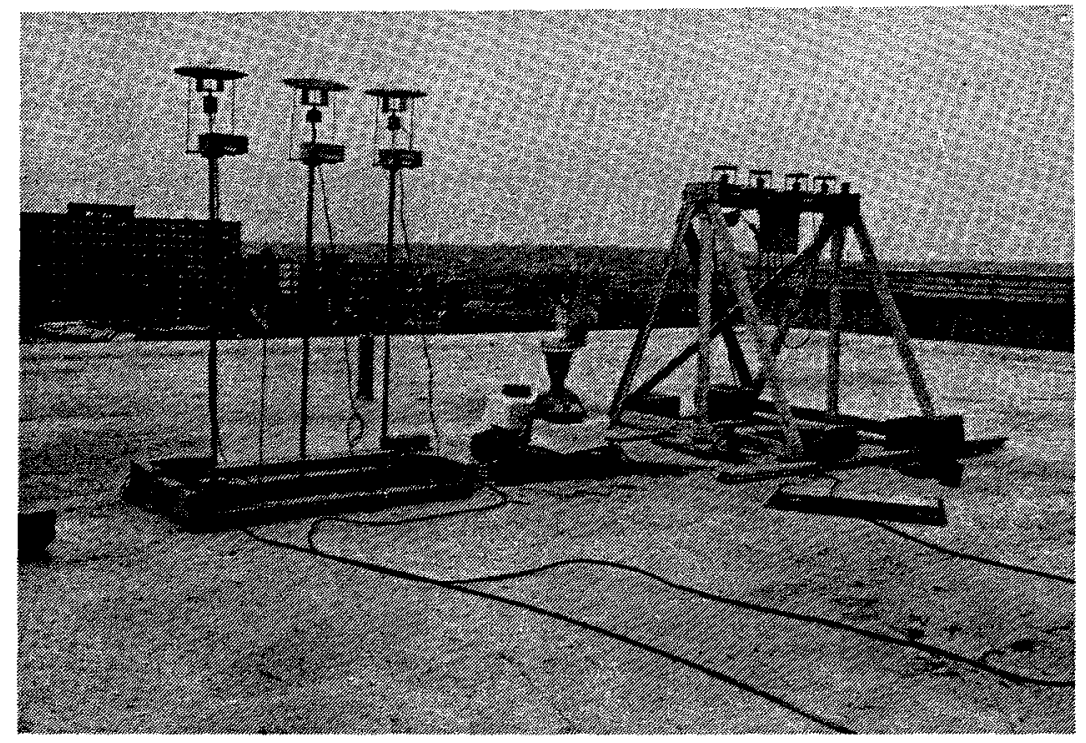

Fig. 1. Rooftop sampler array showing from left to right: 3 rotoslides, the Burkard spore trap and 4 intermittent rotorods. 
was made from 28 July to 14 October 1977 (Fig. 1). The array was operated during 70 intervals of either $9 \mathrm{~h}$ (daytime), $15 \mathrm{~h}$ (night time) or a full $24 \mathrm{~h}$ duration. Presence or absence of rainfall during each sampling period was noted, and sampling proceeded without regard to prevailing weather conditions.

The rotoslides (RS) used fixed cams mandating operation for 1 of every $12 \mathrm{~min}$, and averaged 1600 RPM with an $11 \mathrm{~cm}$ circle of rotation. The rotorods (RR) averaged 2,400 $\mathrm{rpm}$, had $9.6 \mathrm{~cm}$ circles of rotation, and their variable cams were adjusted to $30-\mathrm{s}$ operating periods in each pre-programmed 10 -min cycle. The constancy of each unit's rotational speed, measured with a stroboscopic tachometer, and timer accuracy, (by stopwatch), was confirmed regularly throughout the study. Collecting surfaces of both samplers were coated with silicone grease (Ted Brown Associates) by one technician and stored, prior to use, in dust-proof boxes. After exposure, collecting surfaces were mounted in Calberla's solution $(5 \mathrm{ml}$ glycerin, $10 \mathrm{ml} 95 \%$ ethanol, $15 \mathrm{ml}$ distilled water, 2 drops saturated aqueous solution of basic fuchsin), fitted with coverslips and examined microscopically using transparent stage supports (Benaim, 1973; Ogden et al., 1974). Particles were counted on the entire central $50 \mathrm{~mm}$ of the $1 \mathrm{~mm}$ slide edges and the distal $26 \mathrm{~mm}$ of the $1.6 \mathrm{~mm}$ wide collecting rods.

The Burkard trap (ST) recovered particles on a drum bearing transparent Melenex tape (Burkard Mfg. Co., Ltd.) which was lightly coated with Lubriseal, a xylene-soluble stopcock grease (A. H. Thomas Co., Philadelphia, Pa.) using an acrylic brush. The trap sampled continuously at $10 \mathrm{l} / \mathrm{min}$ onto a surface moving at $2.05 \mathrm{~mm} / \mathrm{h}$; both values were checked regularly and remained constant. Following a 6-day exposure, each tape was cut into 24-h segments, which were affixed to glass microscope slides and mounted in glycerine jelly $(5 \mathrm{~g}$ gelatin, $40 \mathrm{ml}$ distilled water, $4 \mathrm{~g}$ phenol, $156 \mathrm{ml}$ glycerin, $2 \mathrm{ml}$ Calberla's solution). Appropriate 9-, 15- or 24-h segments were examined in two paracentral longitudinal traverses.

For all collections, each identifiable pollen type was enumerated separately; in addition, at a minimum, the following fungus spore types were counted: Alternaria, Epicoccum, Pithomyces and Ganoderma. All resulting data were expressed as "particles recovered $/ \mathrm{m}^{3}$ of air sampled", and no factors reflecting presumed collection efficiencies were applied.

Daily means of 8 RR counts $\left(R_{i}\right)$, of 6 RS counts $\left(S_{i}\right)$, and of 2 ST counts $\left(B_{i}\right)$ were computed, $\mathrm{i}=1, \ldots ., 70$, for Total Particles, Total Pollen, and the individual taxa, Alternaria, Ganoderma, Epicoccum, Pithomyces, Ambrosia and Urtica. The distributions of these mean values were strongly skewed, mandating statistical analysis by nonparametric procedures. To facilitate handling of the data, overall means, medians and ranges were calculated from these daily means.

Mean daily intra-sampler variance was calculated for each sampler type using, initially, the paired counts that each device provided. To facilitate more minute analysis, RS devices were labelled " $A$ ", " $B$ ", and " $C$ " and their component surfaces respectively designated " 1 and $2 ", " 3$ and 4 ", "5 and 6". Rotorod samplers were numbered " 1 ", " 2 ", " 3 " and " 4 ", and for each, one side was marked in red while the other remained unmarked. Lucite rods for these support assemblies were either tipped "red" or left "clear" and data assembled for these categories. For RR and RS, the variance between the two collecting surfaces of 4 and 3 samplers, respectively, was averaged; for the ST, the variance between counts from the two daily traverses was considered intrasampler variance. Mean daily intersampler variance was calculated individually for RR and for RS groups. Daily variance of the mean of two collecting suifaces among 3 (RS) and 4 (RR) samplers was calculated for each of the particle types enumerated. In addition, overall mean intra-and intersampler variances in specific prevalence ranges were calculated for Total Pollen as well as Ambrosia and Urtica grains using both RS and RR data.

Sign tests and Wilcoxon signed rank tests, were performed to examine differences between daily means, derived from the three sampler types for each particle category. The sign test also permitted comparisons of daily mean recoveries among the samplers 
110

and between paired surfaces within each impaction sampler. Spearman's RHO was used to compare daily means and intra- and intersampler variance. In addition, differences between daily means for unlike samplers (RS - RR, ST - RS, ST - RR) were compared with average daily levels indicated by the same samplers (e.g., $(S T+R S) / 2)$.

\section{RESULTS}

By analyzing a large number of samples, it was possible to uncover quite small but consistent differences in collection by individual samplers and their component surfaces. Data describing these comparisons are arranged in Table 1 and show, for example, that particle recoveries by RS-A slightly but significantly exceeded those of $B$ and $C$, while those by RS-B exceeded C with marginal significance. For RS-B, slide 3 recoveries significantly exceeded those of slide 4 by a small margin. Differences within the other two RS were negligible. Overall collections by R R-1 slightly but significantly surpassed those of 2,3 and 4 , while recovery differences among other $R R$ were borderline or insignificant. The two collection surfaces in RR-1 did not differ. In samplers 2, 3 and 4, "clear" readings exceeded matched "red" readings by a small but consistent margin.

Table 1. Differences between particle recovery levels within sampler types, and between paired collecting surfaces on each sampler.

\begin{tabular}{|c|c|c|c|}
\hline & \multicolumn{3}{|c|}{ Difference (total particles $/ \mathrm{m}^{3}$ ) } \\
\hline & Median & Mean & $\begin{array}{c}\text { Sign Test } \\
\mathbf{P}\end{array}$ \\
\hline \multicolumn{4}{|c|}{ Rotoslides } \\
\hline $\begin{array}{l}\text { A-B } \\
\text { A-C } \\
B-C\end{array}$ & $\begin{array}{l}1.64 \\
2.71 \\
0.88\end{array}$ & $\begin{array}{l}2.55 \\
7.87 \\
3.32\end{array}$ & $\begin{array}{l}0.003 \\
0.011 \\
0.003\end{array}$ \\
\hline \multicolumn{4}{|c|}{ Rotoslide surfaces } \\
\hline $\begin{array}{l}1-2(A) \\
3-4(B) \\
5-6(C)\end{array}$ & $\begin{array}{l}0.81 \\
2.26 \\
0.14\end{array}$ & $\begin{array}{l}0.55 \\
4.33 \\
0.33\end{array}$ & $\begin{array}{c}0.019 \\
0.003 \\
\text { ns }\end{array}$ \\
\hline \multicolumn{4}{|c|}{ Rotorods } \\
\hline $\begin{array}{l}1-2 \\
1-3 \\
1-4 \\
2-3 \\
2-4 \\
3-4\end{array}$ & $\begin{array}{r}1.69 \\
2.42 \\
1.40 \\
1.67 \\
-0.01 \\
-1.16\end{array}$ & $\begin{array}{r}3.43 \\
4.92 \\
3.31 \\
1.50 \\
-0.99 \\
-1.55\end{array}$ & $\begin{array}{c}0.005 \\
0.005 \\
0.005 \\
0.025 \\
\text { ns } \\
0.025\end{array}$ \\
\hline \multicolumn{4}{|c|}{ Rotorod surfaces } \\
\hline $\begin{array}{l}\text { C-R (1) } \\
\text { C-R (2) } \\
\text { C-R (3) } \\
\text { C-R (4) }\end{array}$ & $\begin{array}{l}0.45 \\
1.56 \\
2.64 \\
0.87\end{array}$ & $\begin{array}{l}0.56 \\
2.80 \\
4.47 \\
2.87\end{array}$ & $\begin{array}{c}\text { ns } \\
0.005 \\
0.005 \\
0.005\end{array}$ \\
\hline
\end{tabular}


For all particle types and all samplers, the variance (represented in Fig. 2 by standard deviation,) was found to correlate strongly (Spearman rank order correlation, $P<$ 0.00001 ) with prevailing particle levels. Figure 2 compares intra- and intersampler

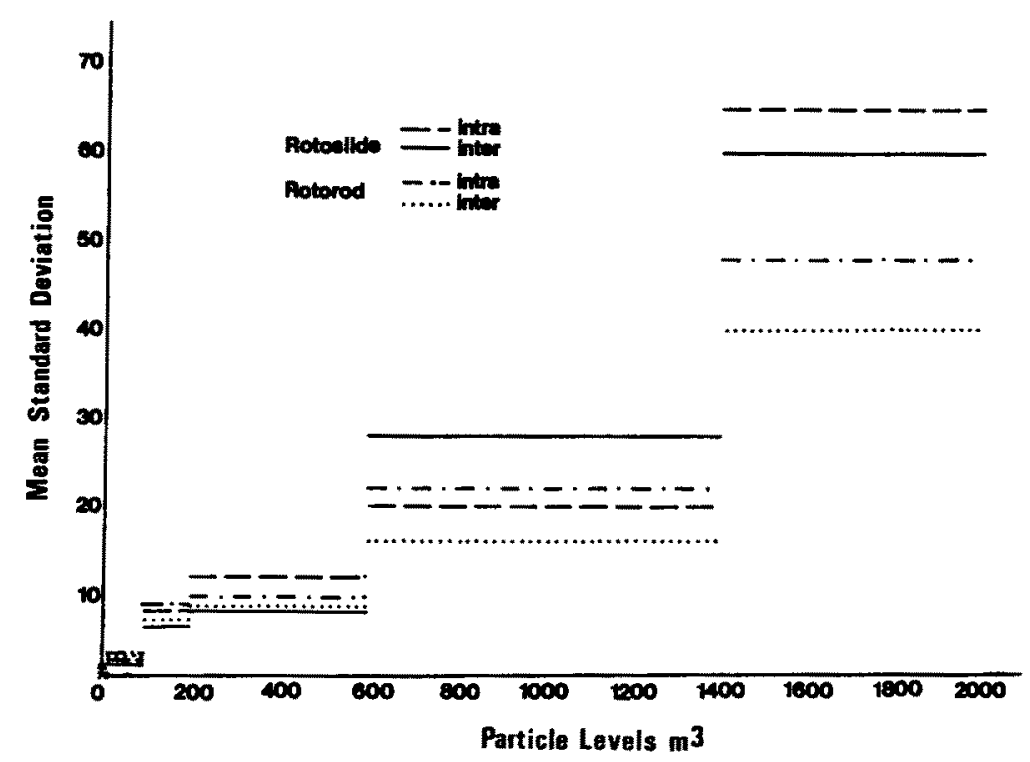

Fig. 2. Mean inter- and intrasampler standard deviations, at 5 levels of particle occurrence for rotoslide and rotorod samplers.

variance for the two impactor types at specific ranges of particle concentration, showing clearly the progression of variance with pollen and spore levels. Up to 1400 particles $/ \mathrm{m}^{3}$, intra- and intersampler variance remained more or less similar for the two sampler types. Above this level, however, RR variances (both intra- and inter-) appeared to be somewhat less than those for the RS.

Mean daily levels of Total Particles recovered by the ST consistently exceeded levels recovered either by RS or RR. Differences between total particle recoveries by RS and by RR were small but consistent (Fig. 3). Burkard trap recoveries of Total Pollen also consistently exceeded both RR and RS, while again, RS slightly surpassed RR with respect to this category (Fig. 4).

Ranges, as well as medians and means for recoveries of all particle types counted are arranged in Table 2 for the three sampler types. Ratios of median recoveries per $\mathrm{m}^{3}$ for the smallest type (Ganoderma) by spore trap and both impactors are 6.9. For the elongate spores of Alternaria, spore trap-impactor ratios of medians were circa 2.2, while for Ambrosia pollen grains, these values were 1.6 and 1.9 for RS and RR collections, respectively.

Data describing possible effects of rain on comparative sampler performance are presented in Table 3. Median recoveries of Total Particles and of Total Pollen by all samplers were lower on rainy than on dry days, as anticipated. The differences between ST and RS collection medians were slightly less for days when rain fell than for precipitation-free periods overall, indicating that, possibly, RS sampling efficiency was less affected by rainfall than was that of the ST. However, $91 \%$ confidence intervals for these medians overlap rendering significance of the observed differences questionable. 


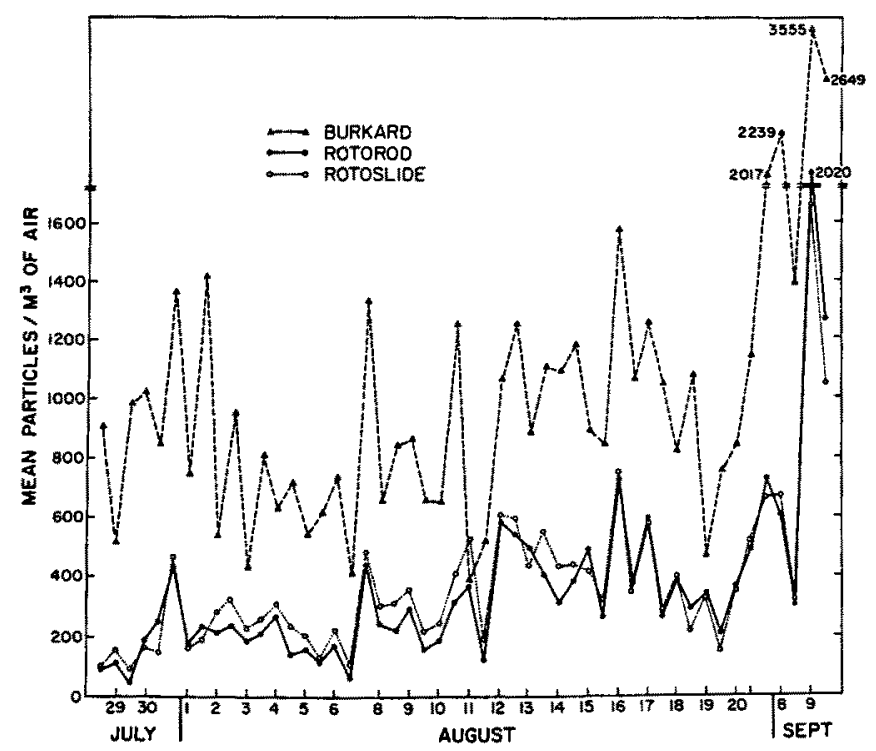

Fig. 3. Mean daily recoveries of Total Particles by the rotoslides, rotorods and Burkard trap.

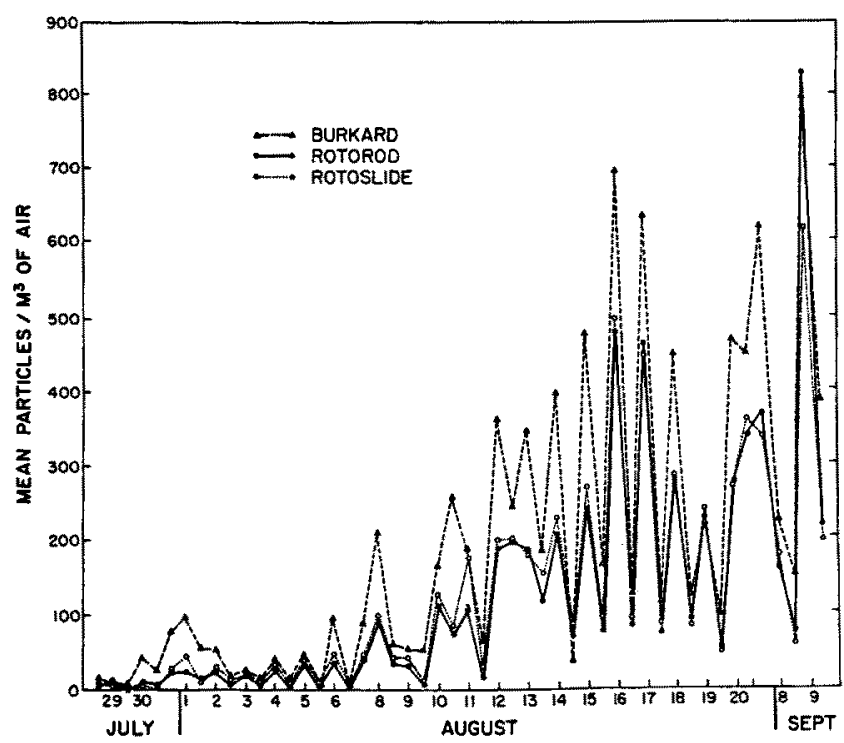

Fig. 4. Mean daily recoveries of Total Pollen by the rotorods, rotoslides and Burkard trap. 


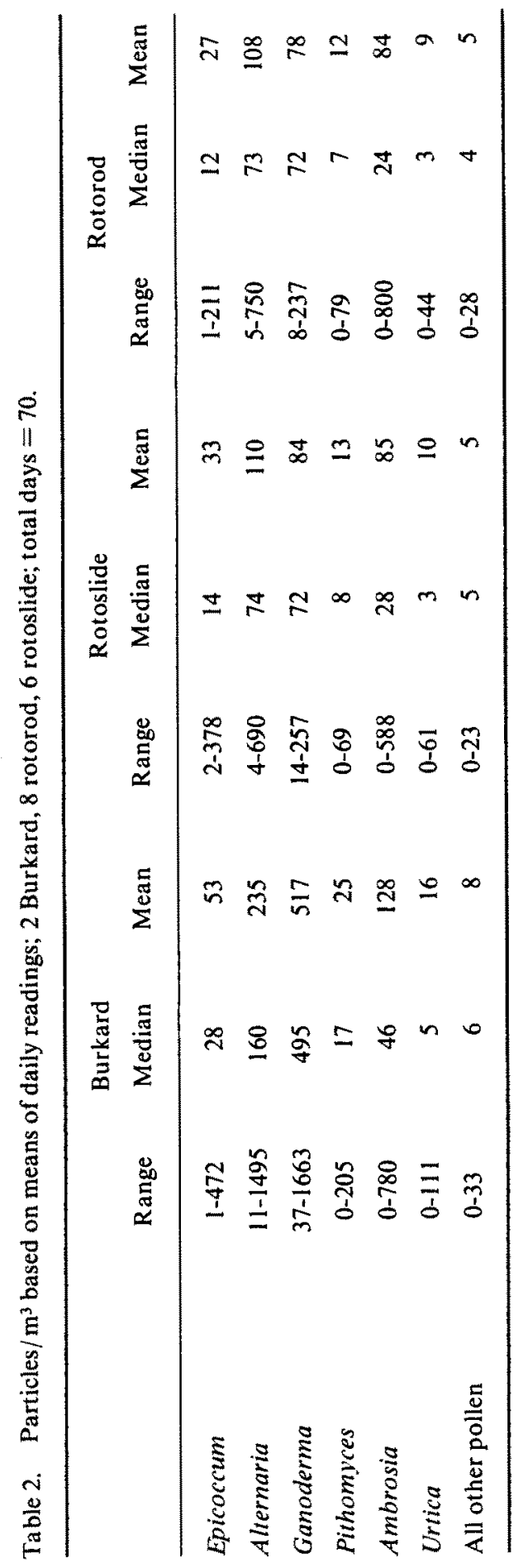


Table 3. Particles $/ \mathrm{m}^{3}$ based on rain day or dry day median levels.

\begin{tabular}{|c|c|c|c|c|}
\hline & \multicolumn{2}{|c|}{ Total particles $/ \mathrm{m}^{3}$} & \multicolumn{2}{|c|}{ Pollen $/ \mathrm{m}^{3}$} \\
\hline & Dry days & Rain days & Dry days & Rain days \\
\hline (n) & (49) & (14) & (49) & (14) \\
\hline \multicolumn{5}{|l|}{ Median } \\
\hline $\begin{array}{l}\text { Burkard } \\
\text { Rotoslide }\end{array}$ & $\begin{array}{l}871 \\
311\end{array}$ & $\begin{array}{l}652 \\
238\end{array}$ & $\begin{array}{l}98 \\
59\end{array}$ & $\begin{array}{l}51 \\
30\end{array}$ \\
\hline \multicolumn{5}{|l|}{ Median difference } \\
\hline B-RS & 559 & 475 & 71 & 10 \\
\hline $91 \%$ Confidence & $492-667$ & $349-546$ & $30-47$ & $2-47$ \\
\hline \multicolumn{5}{|l|}{ Median difference } \\
\hline RS-RR & 41 & 57 & 4 & 8 \\
\hline $\begin{array}{l}91 \% \text { Confidence } \\
\text { interval }\end{array}$ & $19-48$ & $48-94$ & $3-8$ & $3-11$ \\
\hline
\end{tabular}

RS-RR differences clearly increased with respect to Total Particles, but results were equivocal for pollen alone.

Differences between spore trap recoveries and both types of impactor collections decreased as particle levels increased for all categories counted (Spearman rank order correlation, $\mathrm{P}<0.01$ ). However, $\mathrm{R} R-\mathrm{RS}$ differences did not show a similar tendency to diminish with high prevalence levels.

\section{DISCUSSION}

Several recognized theoretical factors affect the particle collecting efficiency of specific volumetric samplers and may, singly or in concert, determine observed differences in recovery among these units (Gregory, 1973; Solomon and Mathews, 1978, Ogden et al. 1974). Continuous, gust-responsive wind orientation is a fundamental requirement for spore trap operation. Furthermore, a flow velocity into the entrance orifice equal to prevailing wind speed is required for unbiased particle collection. Since such "isokinetic" conditions are rarely maintained (Raynor, 1972), it is comforting that the resulting errors of estimation may be evaluated (Watson, 1954) and are lowest for light to brisk wind conditions (using the Burkard trap) and for particles approximating $20 \mu \mathrm{m}$ in size. Rotating arm impactors are unaffected by changes in wind direction and their efficiency seems to vary little at ambient velocities below $25-30 \mathrm{~km} / \mathrm{h}$ (Ogden and Raynor, 1967). More important factors in the performance of these units are sampling surface width and angular velocity (Gregory, 1973). Although comparisons of adhesives have not been reported, these must be adequate to ensure that intercepted aerosol units are retained and do not merely rebound after impact. Collection by the RS and R R which move at 34 $\mathrm{km} / \mathrm{h}$ and $43 \mathrm{~km} / \mathrm{h}$ respectively must provide somewhat more stringent tests of adhesive competence than the Burkard trap which accelerates particles to $21 \mathrm{~km} / \mathrm{h}$ at its entrance 
orifice. Furthermore, surface adhesiveness will tend to fall (Ogden et al., 1974) as particle accumulation proceeds. In this connection it is worth noting that, per $\mathrm{mm}^{2}$ of collection surface, the RS, RR and ST respectively processed $0.026,0.017$, and $0.002 \mathrm{~m}^{3}$ of air in a 9-h operating interval.

Since operating details also can affect calculated results, variables such as impactor speeds and ST throughput were monitored regularly. More subtle differences, such as spring tensions on impactor shields or patterns of acceleration and slowdown defied quantitation, but may have produced the minute intersampler differences observed. Since the RR were in "mint" condition when received, while the RS and ST had seen many years of prior service, factors of relative wear may have influenced our overall results. However, the observed intra- and intersampler differences were quite small (though consistent), suggesting minor or negligible effects.

As noted in previous studies (Burge et al., 1977) the data were strongly skewed and, for each specific type of device, variance rose with increasing levels of particle recovery (Fig. 2). This effect required attention in comparing performances of both similar and dissimilar units, since the three devices took particles with differing efficiency levels. The absence of anything approaching normality in these aerometric data mandated use of non-parametric statistics.

With rare exceptions, spore trap recoveries per $\mathrm{m}^{3}$ sampled consistently exceeded those of either impactor for the particle types ta bulated. Much of this overall advantage (manifest in data of Fig. 3) reflects superior recovery of minute but abundant Ganoderma spores which average $4 \times 7 \mu \mathrm{m}$. The superiority of suction traps in capturing small aerosol units from a moving atmosphere is well documented (Gregory, 1973). However, a spore trap: impactor ratio of 1.5 still remained (Fig. 4) when total pollen recoveries were considerd. These differences are not easily explained, but undoubtedly reflect lower than anticipated impaction efficiency or impaired surface stickiness of the rotorods and slides. Possible decreases in adhesive efficiency as particle loading proceeded may have contributed. Whatever their source, these losses were sufficient to offset theoretical deficiencies of the spore trap in scavenging larger particles from relatively slowly moving air (Ogden et al., 1976; Watson, 1954).

The relationship between apparent aerodynamic size and spore trap/impactor recovery differences is reemphasized in Table 2 . Comparing overall median levels Burkard trap recoveries of Ganoderma spores, Alternaria spores (ca. $10 \times 40 \mu \mathrm{m}$ ) and ragweed pollen grains (about $20 \mu \mathrm{m}$ ) were respectively 7.2 and 1.5 times those of the impactors. Disparities favoring the spore trap for Alternaria were not unprecedented and may reflect a spore fraction, which, though typical in form, is immature and relatively small. Alternatively, these elongate bodies may behave aerodynamically in a way typical of their smallest dimensions (Gregory, 1973).

Since weather type independently affected most particle levels and therefore indirectly influenced sample variance, effects of rain were most difficult to assess. In general, however, the RS seemed least affected of the devices compared. Recovery trends shown in Table 3 become especially suggestive when it is recalled that intersampler differences varied inversely with prevailing particle levels. The approximative trend of ST and RS data on days of rain is a highly atypical finding and suggests relatively poorer particle capture by the Burkard trap in wet weather.

Recoveries of moderately large as well as small aeroallergens by the RS compared favorably with those of the RR overall; although actual margins of difference were quite narrow. This conclusion conflicts with a report by Batchelder (1977) who described much greater differences between the two devices, but made relatively few comparisons and utilized markedly atypical methods of rotorod exposure.

While raising additional questions concerning determinants of collection, our data suggest that recoveries by the various devices may be related tractably. It is evident that the capacity of spore traps to collect small particles far exceeds that of either impactor studied. However, volumetric recoveries of larger spores and pollen grains by the three 
116

devices were substantially closer, though not equivalent. This similarity implies that comparisons of spore trap and impactor-derived prevalence estimates are practical if sampling protocols are defined and, perhaps, simple conversion factors are applied. Furthermore, this study suggests the intermittent retracting rotorod as a useful monitor for particles larger than 8-10 $\mu$. The device has proven durable in limited trials and offers satisfactory shielding from casual particle deposition, adequate rain protection and a relatively trouble-free volumetric capability.

\section{ACKNOWLEDGMENT}

Supported by Research Grant AI-10181 from the National Institute of Allergy and Infectious Diseases, National Institutes of Health, USPHS.

Reprint requests to William R. Solomon, M. D., University Hospital, Ann Arbor, Mich. 48109

\section{REFERENCES}

BATCHELDER, G. L. (1977): Sampling characteristics of the rotorod, rotoslide, and Andersen machines for atmospheric pollen and spores. Ann. Allergy, 39: 18-27.

BENAIM, C. (1973): Staining of biologic airborne particles caught with the rotorod sampler. Ann. Allergy, 31: 618-620.

BURGE, H. P., BOISE, J. R., RUTHERFORD, J. A. and SOLOMON, W. R. (1977): Comparative recoveries of airborne fungus spores by viable and non-viable modes of volumetric collection. Mycopathologia (Den Haag), 61: 27-33.

DINGLE, A. N. (1957): Meteorological considerations in ragweed hay fever research. Fed. Proc., 16: 615-627.

GREGORY, P. H. (1973): The Microbiology of the Atmosphere. 2nd Ed, J. Wiley \& Sons, New York.

OGDEN, E. C. and RAYNOR, G. S. (1967): A new sampler for pollen: the rotoslide. J. Allergy, 40: 1-11.

OGDEN, E. C., RAYNOR, G. S., HAYES, J. V., LEWIS, D. M. and HAINES, J. H.

(1974): Manual for Sampling Airborne Pollen, Hafner Press, New York, 84.

RAYNOR, G. S., (1972): An isokinetic sampler for use on light aircraft. Atmos. Environ., 6: 191-196.

RAYNOR, G. S., HAYES, J. V. and OGDEN, E.C. (1970): Experimental data on ragweed pollen dispersion and deposition from point and area sources. Brookhaven Nat. Lab., Upton, New York 50224, (T-564).

RAYNOR, G. S. and OGDEN, E. C. (1970): The swing-shield: an improved shielding device for the intermittent rotoslide sampler. J. Allergy, 45: 329-332.

SOLOMON, W. R., and MATHEWS, K. P. (1978): Aerobiology and inhalant allergens. (ed. In: Allergy-Principles and Pratice. E. Middleton, Jr., C. E. Reed E. F. Ellis. Mosby Co., St. Louis.

WATSON, H. H. (1954): Errors due to anisokinetic sampling of aerosols. Amer. Ind. Hyg. Ass. Quart., 15: 21-25. 